\title{
A Mode of Government - Enterprise - University - Institute - Employer Cooperation for Innovative Postgraduate Cultivation
}

\author{
Yaqing Tu${ }^{1}$, Huiyue Yang ${ }^{1, *}$, Li Shu ${ }^{1}$, Wangshu $\mathrm{Tu}^{2}$, Baoxin $\mathrm{Chen}^{1}$ \\ ${ }^{1}$ Logistical Engineering University, China \\ ${ }^{2}$ United International College, China
}

Copyright $(2015$ Horizon Research Publishing All rights reserved.

\begin{abstract}
Innovative talent training is an important task of postgraduate education. From the survey of innovative postgraduate training in China, we conclude that there is still much room for improvement in the innovative postgraduate cultivation. The survey shows that insufficient professional practice, simplex training mode and a mismatch between postgraduates' abilities and employers' professional requirement are considered to be defects of the current postgraduate education, among which the training mode is a key factor that determines the talent-training quality. According to the quality composition of innovative talents and academic demands of the postgraduate, factors that determine the training quality of innovative talents have been analyzed and a cooperation mode which combines the effort of government, enterprise, university, institute and employer for innovative postgraduate cultivation is proposed. The connotation and mechanism of the mode are expounded in detail. Four suggestions in implementing the proposed model is also put forward based on the previous practice experience.
\end{abstract}

Keywords Innovative Talents, Postgraduates, Training Mode

\section{Introduction}

Talent is the key to building an innovation oriented country and achieve the Chinese nation's bright prospect on the road to rejuvenation. The cultivation of high-level creative talents is closely related to the whole Nation-building and is a fundamentally strategic task of postgraduate education. "Outline of National Medium-and Long-term Talent Development Plan (2010-2020)" indicates ${ }^{[1]}$ that "in order to cultivate high-level innovative talents and teams, the policy of enterprise-university-institute cooperation training mode is to be adopted through building innovation platform, fostering cooperative education and implementing major projects". It also points out that "innovation project of postgraduate education is to be carried out, high-level talent communication mechanism among universities, institutes and enterprises is to be established, dual tutorial system of enterprise-university-institute cooperation training mode is to be set up." In recent years, enterprise-university-institute cooperation training mode has developed rapidly and markedly, but with increasing economic and social demands for talent and deepening teaching reform in postgraduate education, some deep-seated contradictions in integrating education resources and optimizing training mode have gradually become prominent [2-4]. Issues like how to resolve the contradiction, blaze new trails, further improve the quality of innovative talents, and implement the Outline better, are calling for serious attention and urgent solutions.

Based on the empirical research and combined with the experience of postgraduate education of the University, the paper proposes a postgraduate training mode with cooperation of government, enterprises, universities, institutes and employers.

\section{Research Methods}

Some typical universities in China were selected as the empirical research object to analyze the present situation and influencing factors of innovative postgraduate cultivation. According to the principle of proportional sampling, a total of 5000 questionnaires were given out and 4110 valid copies returned, with $82.2 \%$ response rate. The subjects of the survey include master candidates $(76.59 \%)$ and doctoral candidates $(23.41 \%)$ from such disciplines as art, science, engineering, economics, medicine and management.

\section{Analysis of the Outcome of Innovative Postgraduate Training}


Table 1. Postgraduates' Understanding of Innovative Qualities

\begin{tabular}{|c|c|c|c|c|c|}
\hline Options & Shares(Tot:4110) & Ratio (\%) & Options & Shares(Tot:4110) & $\begin{array}{c}\text { Ratio } \\
(\%)\end{array}$ \\
\hline autonomous learning ability & 2907 & 70.73 & cooperation ability & 2238 & 54.45 \\
\hline scientific research ability & 2888 & 70.27 & social competence & 1502 & 36.55 \\
\hline professional practice ability & 2371 & 57.69 & humanistic quality & 1755 & 42.70 \\
\hline $\begin{array}{c}\text { organization and management ability } \\
\text { speech abilities of both verbal and } \\
\text { written }\end{array}$ & 1644 & 40.00 & $\begin{array}{c}\text { foreign language } \\
\text { aptitude }\end{array}$ & 1409 & 34.28 \\
\hline \begin{tabular}{c} 
interpersonal communication ability \\
\hline
\end{tabular} & 57.18 & 2350 & & 195 & 4.74 \\
\hline
\end{tabular}

The findings of the study are presented in the order of the research questions. First of all the postgraduates' perspective on innovative qualities is mentioned. In succession, we respectively bring forth the postgraduates' self-evaluation on innovative qualities and demands in cultivating the innovation. Then factors influencing the innovative talent cultivation and deficiency in cultivating innovative postgraduates are analyzed in turn.

\subsection{General Perspective of the Postgraduate on Innovative Talent}

Postgraduates' perspective on innovative qualities, which directly reflects their view of talent and personal development goal, greatly influences the training quality of innovative talent.

Table 1 displays that abilities of scientific research, autonomous learning, professional practice, interpersonal communication and cooperation are widely recognized as qualities of innovative talents. Meanwhile, humanistic quality, speech abilities of both verbal and written, organization and management ability, foreign language aptitude, social competence are also considered as critical. The result shows that postgraduates have a comprehensive and profound understanding of innovative quality. In terms of the recognition ratio of abilities, autonomous learning ability and scientific research ability rank the top which indicates that academic research innovation is deemed as dominantly essential in innovative talents' quality, while professional practice ability, interpersonal communication ability and cooperation ability have been recognized by more than half of respondents which shows that excellent communication skills are regarded as indispensable for innovative talents.

\subsection{Self-evaluation of Postgraduates on Innovative Qualities}

When asked about "How do you evaluate your innovative quality", $6.21 \%$ of the respondents are dissatisfied, $42.91 \%$ regard it ordinary, $38.12 \%$ are generally satisfied and only $12.76 \%$ feel satisfied.

Table 2. Self-evaluation of Postgraduates on Innovative Quality

\begin{tabular}{|c|c|c|c|c|}
\hline Options & satisfied & $\begin{array}{c}\text { generally } \\
\text { satisfied }\end{array}$ & ordinary & dissatisfied \\
\hline $\begin{array}{c}\text { Shares } \\
\text { (Tot:4110) }\end{array}$ & 533 & 1575 & 1764 & 264 \\
\hline Ratio (\%) & 12.76 & 38.12 & 42.91 & 6.21 \\
\hline
\end{tabular}

Those who are satisfied with their own creativity account for $50.88 \%$ in total, but there are still $49.16 \%$ of respondents considering their innovative quality ordinary or dissatisfied. The data reveals that although efforts on innovative postgraduate training have been notably recognized, there is still much room and a pressing need for improving the innovative postgraduate training.

\subsection{Postgraduates' Demands in Cultivating the Innovation}

Postgraduates' demands and expectations during their education need to be greatly emphasized. The survey indicates that, When asked about "what are your top concerns in their postgraduate study ", $76.79 \%$ of the participants are concerned about enhancing their comprehensive qualities, while $54.72 \%$ prefer to scientific research ability and academic quality, $41.65 \%$ to employment and professional development, and $37.86 \%$ to the degree reception. As shown in Table 3, when it comes to "In which aspects would you expect to be guided in your study", $68.56 \%$ of the participants prefer to professional skills, $46.98 \%$ choose employment and professional development, and $25.18 \%$ choose entrepreneurship. The results indicate that postgraduates tend to promote their development in an all-round way, which can be attributed to the increasing economic and social demands for innovative talents. It is also due to the fact that comprehensive quality is the core competence of innovative personnel which is hard to cultivate but often be neglected. 
Table 3. Postgraduates' demands in cultivating innovation

\begin{tabular}{|c|c|c|c|c|c|}
\hline \multicolumn{2}{|c|}{ Directions concerned } & \multicolumn{3}{c|}{ Directions expected to be guided } \\
\hline Options & $\begin{array}{c}\text { Shares } \\
\text { (Tot:4110) }\end{array}$ & $\begin{array}{c}\text { Ratio } \\
(\%)\end{array}$ & Options & $\begin{array}{c}\text { Shares } \\
\text { (Tot:4110) }\end{array}$ & $\begin{array}{c}\text { Ratio } \\
(\%)\end{array}$ \\
\hline degree & 1556 & 37.86 & professional skills & 2818 & 68.56 \\
\hline $\begin{array}{c}\text { scientific research achievement and } \\
\text { academic quality }\end{array}$ & 2249 & 54.72 & $\begin{array}{c}\text { employment and professional } \\
\text { development }\end{array}$ & 1931 & 46.98 \\
\hline $\begin{array}{c}\text { comprehensive qualities } \\
\text { employment and professional } \\
\text { development }\end{array}$ & 3156 & 76.79 & entrepreneurship & 1035 & 25.18 \\
\hline not concerned & 67 & 1.63 & humanistic quality & 1741 & 42.36 \\
\hline
\end{tabular}

Table 4. Factors Influencing the Innovative Talent Cultivation

\begin{tabular}{|c|c|c|c|c|c|c|}
\hline Options & $\begin{array}{c}\text { government and school } \\
\text { policy }\end{array}$ & $\begin{array}{c}\text { training } \\
\text { mode }\end{array}$ & $\begin{array}{c}\text { curriculum } \\
\text { design }\end{array}$ & tutor quality & $\begin{array}{c}\text { research } \\
\text { conditions }\end{array}$ & others \\
\hline Shares(Tot:4110) & 2308 & 3617 & 2106 & 2207 & 2083 & 90 \\
\hline Ratio (\%) & 56.16 & 88.00 & 51.24 & 53.70 & 50.68 & 2.19 \\
\hline
\end{tabular}

Table 5. Deficiency in Cultivating Innovative Postgraduates

\begin{tabular}{|c|c|c|c|c|c|c|c|}
\hline Options & $\begin{array}{c}\text { simplex } \\
\text { training } \\
\text { mode }\end{array}$ & $\begin{array}{c}\text { insufficient } \\
\text { practice } \\
\text { opportunities }\end{array}$ & $\begin{array}{c}\text { irrelevance to } \\
\text { employers' } \\
\text { requirements }\end{array}$ & $\begin{array}{c}\text { management } \\
\text { mode hindering } \\
\text { personality } \\
\text { development }\end{array}$ & $\begin{array}{c}\text { inadequate } \\
\text { tutor } \\
\text { guidance }\end{array}$ & $\begin{array}{c}\text { research } \\
\text { conditions }\end{array}$ & others \\
\hline Shares(Tot:4110) & 2458 & 2719 & 1926 & 2284 & 1024 & 966 & 82 \\
\hline Ratio (\%) & 59.81 & 66.16 & 46.86 & 55.57 & 24.91 & 23.50 & 2.00 \\
\hline
\end{tabular}

\subsection{Factors Influencing the Innovative Talent Cultivation}

There are a great many factors influencing innovative talent training. Thus, to figure out the key factor and take corresponding measures are vitally important to improve the quality of talent training. As shown in Table 4, training mode accounting for $88.00 \%$ ranks first among those factors, followed by the government and the school policy $(56.16 \%)$, tutor quality $(53.70 \%)$, curriculum design $(51.24 \%)$, research conditions $(50.68 \%$, ) and other factors $(2.19 \%)$. Thus, the key to promoting the quality of innovative postgraduates is to combine policy, curriculum design, tutor team, research conditions and other factors.

\subsection{Deficiency in Cultivating Innovative Postgraduates}

When it comes to "the deficiency in training innovative postgraduates of your university" (as shown in Table 5), $66.16 \%$ of those questioned hold that professional practice opportunities for postgraduates are insufficient, $59.81 \%$ hold that the training mode is relatively simple, $46.86 \%$ think there is a mismatch between their abilities and the employer's professional requirements, $55.57 \%$ feel the school management is not conducive to their personality development, $24.91 \%$ think more guidance from tutors are needed, $23.50 \%$ suggest that the research conditions remain to be improved, and $2.00 \%$ think deficiency exists in other training aspects. The result indicates that the current postgraduate training emphasizes more on theoretical education rather than professional practice. Actually, it is an indisputable fact that theoretical innovation is incompatible with engineering practice ${ }^{[5]}$. It is mainly due to the outdated educational concept and inadequate educational resources, while the solitary school-based training mode is the direct cause. Under such circumstances, the irrelevance of innovative talent training objective to the professional requirements makes it imperative for employers to retrain graduates. The improvement of management mode and research conditions is expected by a large number of postgraduates. Inadequate tutor guidance which is caused by high teacher-student ratio remains a common problem and dissatisfaction among students.

To sum up, with the development of postgraduate innovation education, the training quality of innovative postgraduates has been notably enhanced, but there is still much room for improvement. The "enterprise-university-institute cooperation training mode" remains to be further optimized to meet the needs of building an innovation-oriented country. According to the quality composition of innovative talents and academic demands of postgraduates, factors that determine the training quality of innovative talents have been analyzed and a mode of government-enterprise-university-institute-employer cooperation for innovative postgraduate cultivation is proposed ${ }^{[6]}$, which aims to further enhance the quality of innovative talent training by strengthening policy guidance, establishing closer contact with employers and integrating various educational resources. 


\section{Connotation of the Government - Enterprise - University - Institute - Employer Cooperation Training Mode}

The government-enterprise-university-institute-employer cooperation training mode organically combines the efforts of postgraduate training institutes, education departments, enterprises, research institutes, technical achievement application units and employers, make full use of their advantages in talent training, and integrate theoretical research-oriented school environment and practice-oriented production and application environment in the whole process of postgraduate cultivation. The training mode (Fig. 1) emphasizes combining theory with practice closely and requires each party to become deeply associated. Thus, the postgraduate will be able to have access to the newest and the most needed technique from the line of industrial application and production practice, identify the research topic of great value, gain the policy support (including funds) from the government, obtain the training requirement and target from employers, and integrate equipment and technology in enterprises. After considering engineering technology needs and personnel training requirements, more targeted and purposeful training programs and curriculum systems are designed for the postgraduate. In the training process, postgraduates begin with theoretical and technological acquisition in a university and continue to engage in the scientific research and practice in an institute or an enterprise so as to apply the theory into practice. Learning from the practical experience in engineering, postgraduates are supposed to summarize the key problem in research and make theoretical innovation. Postgraduates' innovative capabilities, in the interactive training process of "theory-practice-theory", are expected to be notably enhanced.

As shown in Figure 1, innovative postgraduate cultivation is taken as the central goal of "government - enterprise university - institute - employer cooperation training mode". All parties get involved in two-way interaction under the principle of mutual benefit and reciprocity. The government and education departments provide policy guidance and necessary financial support in the training process. Enterprises offer the practical teaching base and internships and make the transformation of scientific research achievements possible. Schools provide postgraduates with teachers, experimental platforms and academic environment. Scientific research institutes make research projects available for students through joint training or project cooperation mode. Employers provide timely and frequent feedback in the form of the innovative quality assessment and job requirements so as to promote the research and optimize the talent training scheme.

\section{Innovative Talent Training Mode with Government - Enterprise - University - Institute - Employer Cooperation}

It is quite necessary to integrate educational resources, such as universities, the government, enterprises, research institutes and employers, and develop an all-round, multi-perspective, multi-channel training mode in the process of cultivating innovative talents. The university that the author works for engages itself actively in teaching reform of postgraduate and explores the government-enterprise-university-institute-employer cooperation training mode. Under the guidance of school policy, "Postgraduate Innovation and Practice Workshop" has been established, taking disciplines of information technology, oil and natural gas engineering, civil engineering as pilot areas. Based on the existing school resources of disciplines and teachers, it has cooperated with information technology companies in Chongqing, China in scientific research and project development. Moreover, it has established a mechanism for postgraduates' internship in an acting capacity with many employers ${ }^{[7]}$ and notable results have been achieved in innovative postgraduate cultivation. Based on the findings of the questionnaires and recent practices of the author's university, some suggestions for "government-enterprise-university-institute-employer cooperation training mode" are hereby put forward.

\subsection{Integrate Educational Resources and Establish a "win-win" Cooperation Mechanism for Education}

The advantage of "government - enterprise - university institute - employer cooperation training mode" lies in the deep integration of educational resources. However, the roles and motivation of the parties involved in are different. Only through upholding the win-win approach and meeting their expectations can the cooperative training mode develop sustainably.

On the one hand, all involved parties should make their own position clear, not to be offside or absent in the cooperation. The government and education departments should be committed to creating favorable environment for cooperation, emphasizing on policy design for cooperation, rather than interfering with operation and implementation of cooperative education. Enterprises are expected to offer postgraduates timely information of market demands and enable them to select research topics closely linked to industrial application. Universities are supposed to act as the main body in innovative postgraduate training, while the research institutes which are not qualified for postgraduate training should play a collaborative role and share the technical advantage through project cooperation. Employers, as the platform for testing the quality of scientific achievements and talent training, are required to give timely feedback for the sake of training scheme optimization. 


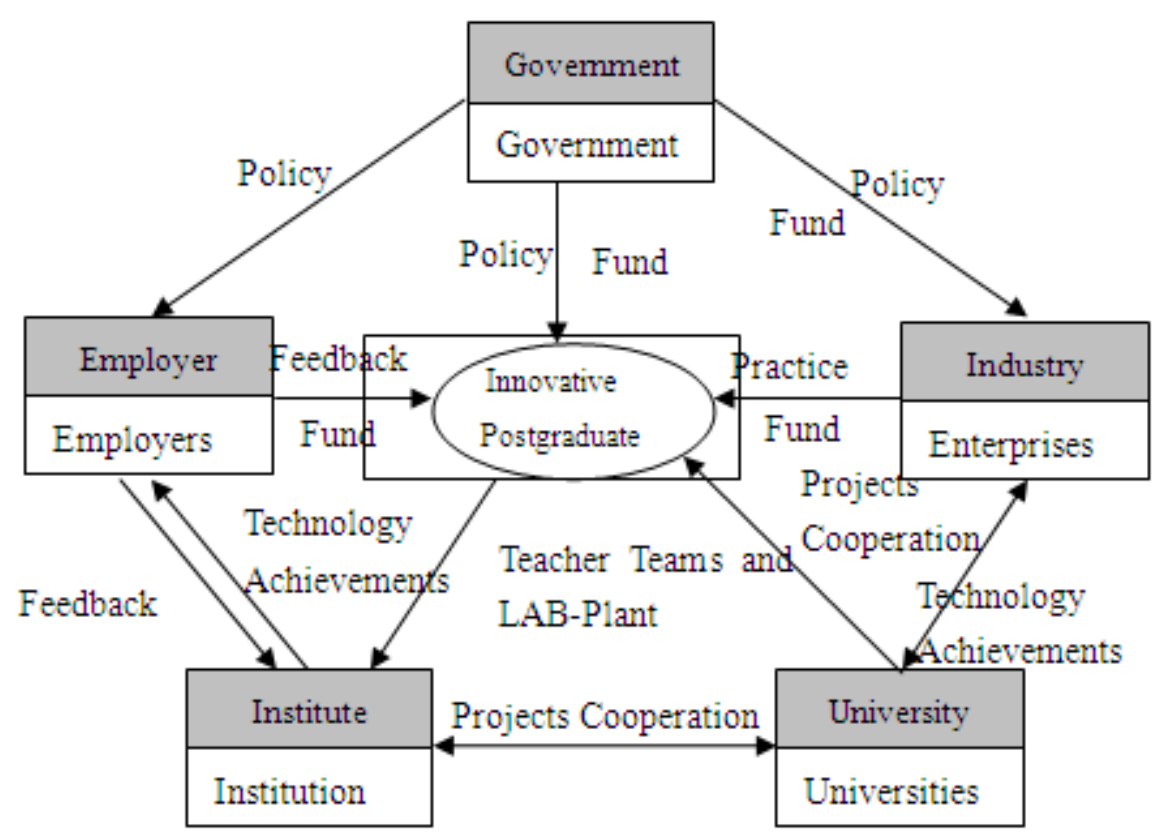

Figure1. Diagram of the "government-enterprise-university-institute-employer cooperation training mode"

On the other hand, all parties should cooperate closely to build an open channel for information exchange and sharing. In so doing, they can integrate their own resources, give full play to their respective advantages, and finally attain the goal of building a "government - enterprise - university institute - employer cooperation training mode".

\subsection{Improve Scientific Research Conditions and Promote the Commercialization of Scientific and Technological Achievements by Relying on Their Joint-built Entities}

The cooperation training mode has been put into practice for many years, but $29.37 \%$ of questioned postgraduates still consider that there are disconnections among enterprises, universities and research institutes; $51.42 \%$ maintain that the mode needs to be deepened, and only $19.21 \%$ think that it has made telling effects. As regards conditions for scientific research, $50.68 \%$ of respondents believe that the scientific research condition can hinder the training of innovative talent, while $23.50 \%$ argue that the research conditions need improving. In the process of employing the "government-enterprise-university-institute-employer cooperation training mode", we can give full scope to the roles of high-tech enterprises, $\mathrm{R} \& \mathrm{D}$ institutions (such as $\mathrm{R}$ \& D centers, pilot base), engineering research centers and key laboratories, high-tech industrial parks and other forms of entities, to share educational resources and improve research conditions for training postgraduates. For the sake of avoiding disconnection among the involved parties, special attention should be paid to the leading role of "enterprises" as well as the social and economic values of scientific innovation. And it is imperative to ensure the applications of knowledge and research and focus on the use of sources like the industrial incubator to facilitate the transformation of innovative achievements into productive forces.

\subsection{Attach Importance to Internship and Practical Training and Build Practice Bases for Innovation}

Innovation is not water without a source, and the cultivation of innovative talent is in need of platforms and environment for innovation. The cultivation of innovative talents can be realized by establishing bases for innovation practice, being guaranteed by rules of innovation cultivation, nursing innovation practice team, and expanding the training space via scientific project research and extracurricular scientific and technological practice activities. As to the construction of innovation practice bases, we can learn from the successful experience of some universities ${ }^{[8-10]}$, lay out a set of regulations for postgraduate innovation practices, and supply postgraduates with necessary support such as experimental space, equipment, materials, fund and tutor guidance. At the same time, with the support of the government, enterprises, institutes and employers, a special innovation fund for postgraduates can be set up in innovation practice bases so as to help students writing academic dissertations and making inventions. An innovation incentive mechanism can also be established according to the discipline advantage in order to encourage postgraduates to select tough research topics and help manage their worries about research risks from the system level. The second academic class for competition can be opened to create a better atmosphere for innovation practice.

\subsection{Conduct Joint Training and Give Nonstop Instructions}

“Government-enterprise-university-institute-employer 
cooperation training mode" is a "theory-practice-theory" process which postgraduates must go through. The diversity of training units and the differences in the training process make joint training an important approach to practice. In such a process, as postgraduates have to get involved in practices designated by enterprises and employers, their tutors of the university can hardly guide them all the way. Thus, the tutor guidance from enterprises and employers will directly affect the quality of innovative talent training. The survey shows that $53.70 \%$ of respondents think that the tutor quality exercises great influence over the innovative talent training and $24.91 \%$ claim that their tutors give insufficient guidance. Based on this, the ranks of teachers should be built up in implementing cooperative education. On the one hand, this can be settled by improving the teambuilding of teaching staff, controlling the number of students each tutor guides, and sending teachers to work in an acting capacity for employers. On the other hand, a double-tutorial or multi-tutorial mechanism can be formed with the involvement of experts recommended by enterprises or employers and evaluated by schools according to relevant conditions and procedures. In such a manner, major advantages of different tutors can be capitalized and consistent guidance to postgraduates can be ensured in the training process.

\section{Conclusions}

The training of innovative postgraduates is a long-term, complicated and systematic project, which needs to keep pace with the times, constantly improve educational concepts, integrate all education resources and optimize the training mode. Through drawing on past experience, we should carry forward the cause and remain bold in innovation, so as to blaze a trail in the field of postgraduate education with Chinese characteristics, where innovative talents can come out in succession.

\section{Acknowledgements}

This work is supported by postgraduate education teaching reform key projects of Chongqing, China (Yjg110103) and education teaching reform projects of Logistical Engineering University.

\section{REFERENCES}

[1] Summary of National Medium- and Long- term Talent Development Project (2010-2020) [EB/OL]. http://www.china.com.cn/policy/txt/2010-06/07/content_201 97790.htm, 2010-06-07.

[2] T. Qiping, D. Jian, Z. GHao. State and Stratefies of Fostering Chinese Postgraduate Students' Innovation Ability-Based on a Survey of Twenty-two 985 Project Universities. Jouranal of Graduate Education, Vol.15, No.3, pp:41-46,2013.

[3] X. Cui, L. Xing. Research on Enterprise-University-Institute Cooperation Training Mode and Constraints of Our Country-Based on Tripartite Perspective of Government, Enterprise and University. Science and Technology Management Research, No.6, pp:45-47,2010.

[4] X. Yilin. Analysis of Information Asymmetry of Enterprise-University-Institute Cooperation Training Mode, Higher Education for Engineering, Vo.6, pp:45-47, 2010.

[5] L. Yan, S. Meiping, W. Tao, X. Xin, D. Bin. An Exploration of Improving Innovative Abilities of the Post-Graduate Students Based on Scientific Research Practice, Journal of Higher Education Research, Vol.32, No.3, pp:47-49,2009.

[6] T.Yaqing, M.Yuwen, Government-Enterprise-University-Ins titute-Employer Cooperation for Training Cadet Innovative Talents, Boost the Theoretical Innovation of Military Education and Postgraduate Education,No.8, pp:171-175,2009.

[7] "Exploration and Practice of Government-Enterprise-Univer sity-Institute-Employer Cooperation for Training Engineering Postgraduate Innovative Talents", Fist prize of Chongqing Education Achievement Awards, Chongqing Municipal People's Government. [EB/OL]. http://www.cq.gov.cn/gw/FaguiQuery/Main.aspx, 2013.7.20

[8] F.Zhenyun, Z.Yusong, Research on Postgraduate Innovative Base of "Chongqing University Mode", China Higher Education Research,No.5, pp:37-39,2004.

[9] W. Yue, F.Xiujuan, M.Qishuang. Practice and Exploration of - Taking Beijing University of Aeronautics and Astronautics for an Example,Academic Degrees and Graduate Education,No.1, pp:16-20,2012.

[10] L.Huaqi, L. Bin, L.Hao-ran, Z.Yucun, S.Peiming. The Graduate Training Mode Based on a Comprehensive Practice Platform. Journal of Graduate Education,Vol.12, No.6, pp: 33-35\&51,2012. 